\title{
ATATÜRK'ÜN BAZI KURULUŞLARIN HATIRA DEFTERLERINE YAZDIKLARI
}

Yrd. Doç. Dr. Hülya BAYKAL

Kurtuluş Savaşı'nın başından itibaren, Atatürk'ün ziyaret ettiği kuruluşlar için, O'nun görüşlerini almak, izlenimlerini belirlemek büyük değer taşıyan bir olaydı. Çünkü Atatürk, bu ziyaretleri esnasında ilgililerden sadece bilgi almakla kalmıyor, kuruluşların gösterdikleri eksikler, yapmaları gereken çalışmalar hakkında da onları uyarıyordu. Bu bakimdan hatira defterlerine yazdığı yazılar, Atatürk' ün çeşitli yurt sorunları hakkında görüşlerini belirlemek, O'nun geleceğe yönelik düşüncelerini değerlendirmek açısından da değer taşımaktadır.

Şunu da belirtmeliyiz ki, Atatürk’ün gerek Millî Mücadele gerekse onu izleyen yıllar içinde ziyaret ettiği çeşitli kuruluşların defterlerine yazdıklarının pek azı günümüze ulaşabilmiştir. Büyük Adam' ın birçok kurumun hatıra defterine yazdığı değer biçilmez yazılar, ne yazık ki büyük ihmal sonucu korunamamıştır.

Bu araştırma, bu konuda daha önce yapılan bir çalışmada* bulunmayan bazı metinleri kapsaması bakımından Atatürk ve Atatürkçülükle ilgili incelemelere katkısı olacağı düşüncesiyle yayınlanmaktadir.

\section{AFYON KARAHISAR TÜRKOCAĞI'NIN HATIRA DEFTERINE YAZDIKLARI}

24 Mart 1923

Afyon Karahisar Türkocağı azasıyla bugün müşerref oldum. Ocak'ta geçen dakikalar birbirimizi anlamak ve dinlemek için güzel vesileler bahşetti. Çok memnunum. Bilhassa Karahisar halkının,

*Atatürk'ün Hatıra Defterlerine Yazdıkları, Utkan Kocatürk, Edebiyat Yayınevi, Ankara 1971. 
gençliğinin, münevverânının kıymetli tahąssüsleri hakimiyet-i milliyenin muhafazasındaki kat'i azimlerini kendi heyecanlı lisanlarından işitmek benim için pek çok inşirah ve itminanı mucip olmuştur. Karahisar-ı Sahip halkı cidden memleketlerine, millî mefkûreye sahiptirler. Karahisar, mevki-i mühimminin icap ettirdiği bütün inkişaflara mazhar olacaktır. Çünkü burada yanan ocak, Türk'ün en temiz kalbinden feyz alıyor.

Gazi M. KEMAL ${ }^{1}$

\section{II \\ SAMSUN MUALLIMLER BİRLIĞI'NIN HATIRA DEFTERINE YAZDIKLARI}

Samsun, 22 Eylül 1924

Samsun Muallimler Birliği Heyeti'ni tebrik ederim. Gösterdikleri münevver birlik asarı takdire sezadır. Samsun evlâtları bu birliğin feyzinden ne kadar müstefit olacaklardır.

Bütün Türkiye'ye şamil Muallimler Birliği'nin, bütün milleti münevver birlik haline getirdiği zaman, Türk milletinin nasıl bir demir kitle olacağını düşünmek cidden büyük zevk ve saadettir.

Bu kadar nurlu, bu kadar mesut netice verecek bir hedefin rehberlerini hürmetle selâmlarım.

Gazi Mustafa KEMAL2

III

KAYSERI LISESI'NIN HATIRA DEFTERINE YAZDIKLARI

Kayseri, 14 Ekim 1924

Kayseri Lisesi'ni müdürüyle, muallimleriyle, bütün talebesiyle Cumhuriyetin ateşli, feyizli bir ocağı bulduk.

Lâtife Gazi Mustafa KEMAL

Gazi Mustafa KEMAL ${ }^{3}$

1 Atatürk ve Büyük Zafer, Osman Attilâ, Ankara 1972, s. 58).

2 Samsun il Yıllığı, 1967, s. 134. 1969.

3 Atatürk Kayseri'de, Ömer Çelebi, Ankara, 1973; Atatürk Evi, Ömer Yörükoğlu, Beğendik Kültür Hizmetleri: 2 (tarihsiz) 
IV

\section{MUDANYA HALK FIRKASI DEFTERINE YAZDIKLARI}

29 Eylül 1925

Muhterem Mudanyalıların geçen intihapta gösterdikleri vefayı ve programımıza şuurlu irtibatını ispat eden hareketlerini lisan-ı şükran ve takdir ile kaydetmeyi vazife addeylerim.

Gazi Mustafa KEMAL ${ }^{4}$

\section{BALIKESIR TÜRKOGAĞI'NHN HATIRA DEFTERINE YAZDIKLARI}

8 Ekim 1925

Balıkesir Türkocağı'nda genç, münevver, ateşin azasının samimî huzurlarıyla geçirdiğim kıymetli dakikaları daima mütehassis olarak hatırlayacağım. Çok müstaid ve cevherli milletimizin harsını yükseltmekte Ocak'ın mutasavver teşebbüsatını büyük memnuniyetle dinledim. Millete asrın medeniyetinden bugünkü ve yarınki icabatını hüsn-i telkine Balıkesir Türkocağı'nın feyyaz bir menba, muvaffak bir müessese olmasını temenni ederim.

Gazi Mustafa KEMAL ${ }^{5}$

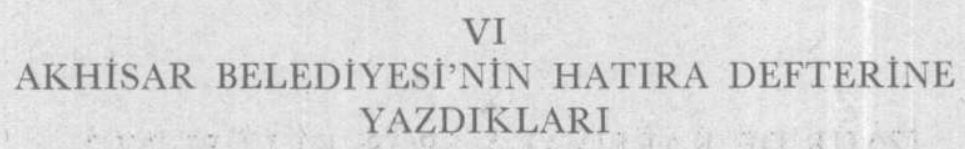

10 Ekim 1925

Akhisar'da geçirdiğim birkaç saatlik zaman çok uzun zamanlarda ancak vücut bulabilecek çok kuyvetli, çok kıymetli bir hatıra yaratmaya kâfi gelmiştir. Memleket güzeldir, halk temiz, samimî ve münevverdir. Hiss-i vefa bu münevver muhitin havasında ne kadar derin bir imtizaçla mündemiçtir.

Gazi Mustafa KEMAL 6

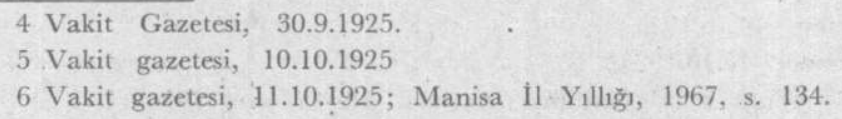




\section{VII \\ IZMIR'DE KARŞIYAKA SPOR KULÜBÜ'NÜN HATIRA DEFTERINE YAZDIKLARI}

13 Ekim 1925

Karşıyaka Spor Kulübü'nde karşı karşıya bulunduğum gençlik iftihara çok şayandır. Bu gençlik muvacehesinde istikbalin kuvveti, saadeti ne bariz görülmektedir.

Gazi Mustafa KEMAL ${ }^{7}$.

\section{VIII \\ IZMIR KIZ LISESI HATIRA DEFTERINE YAZDIKLARI \\ 13 Ekim 1925}

Müdür hanım ve bey muallimlerin ciddî, isabetli mesaisinin asarı sühûletle ve takdirde görülmektedir.

Gazi Mustafa KEMAL ${ }^{8}$

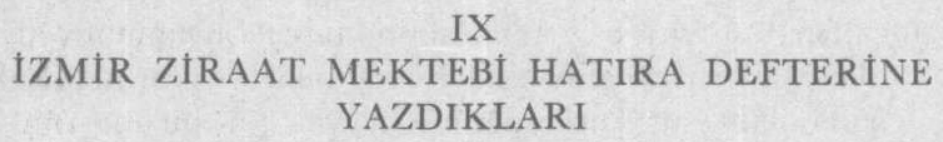

15 Ekim 1925

Izmir Ziraat Mektebi muktedir ellerde feyizli eserini göstermiştir. Ziyaretimden memnunum.

Gazi Mustafa KEMAL 9

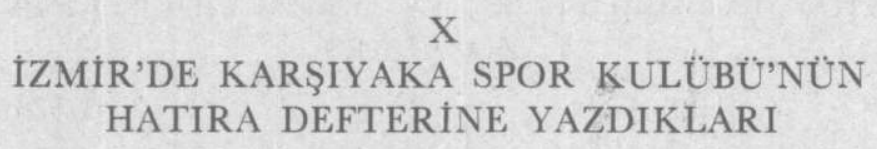

24 Haziran 1926

Bu defaki ziyaretimde geçen aylarda masruf mesai ve himmetin kıymetli asarını gördüm. Teşekkür ve tebrik ederim.

\section{Gazi Mustafa KEMAL ${ }^{10}$} 1981.

7 Vakit gazetesi, 15.10.1925; Belgeleri ile Türk Spor Tarihinde Atatürk, Halùk San,

8 Vakit gazetesi, 14.10 .1925

9 Vakit Gazetesi, 16.10.1925

10 Belgeleri ile Türk Spor Tarihinde Atatürk, Halûk San, 1981. 


\section{$\mathrm{XI}$ \\ CERRAHPAŞA HASTANESI HATIRA DEFTERINE YAZDIKLARI}

14 Aralık 1930

Gördüklerimden memnun oldum. Temizlik, intizam, ciddî mesai takdire şayandır.

Gazi Mustafa KEMAL 11

\section{XII \\ KIRKLARELI TÜRKOCAĞI'NIN HATIRA DEFTERINE YAZDIKLARI}

21 Aralık 1930

Kırklareli Türkocağı'nda çok kıymetli arkadaşlarla geçirdiğim zamanın hatırasını ölmez hislerle saklayacağım.

Gazi Mustafa KEMAL 12

\section{XIII \\ BOLU HALKEVI'NIN ŞEREF DEFTERINE YAZDIKLARI}

18 Temmuz 1934

Bolu Halkevi'nde bir gece kaldım. Bolu'nun güzelliğinden, halkın coşkun sevinçlerinden çok mütehassis oldum.

Gazi M. KEMAL ${ }^{13}$

\section{TÜRK HAVA KURUMU'NUN SSEREF DEFTERINE YAZDIKLARI}

29 Ekim 1936

Cumhuriyet Bayramı

Bugünkü geçit resmi, T.H. Kurumu için, verimli çalışmalarını göstermek hususunda güzel bir vesile oldu. Türk Kuşu'nun pla-

11 Vakit gazetesi, 15.12 .1930

12 Kırklareli Il Yıllığı, 1967, s. 195; Atatürö Kırklarelinde, Nazif Karaçam, İstanbul 1969.

13 Cumhuriyetin 15. Yllinda Bolu, 1938, s. 39. 
nör uçuş ve akrobasileri, paraşütçülerin hareketleri parlak ve çok ümit verici idi.

Kurum Başkanı F. Bulca'yı ve Kurum'un ve T. Kuşu'nun bütün mensuplarını tebrik eder, çalışmalarında yüksek başarılar dilerim.

K. ATATÜRK ${ }^{14}$

14 Havacilik ve Spor, sayı: 227-228, Kasım 1938 (Atatürk'ün elyazısı ile klise). 